\title{
Structure and Molecular Species Composition of Three Homologous Series of $\alpha$-Mycolic Acids from Mycobacterium spp.
}

\author{
By KENJI KANEDA, ${ }^{1}{ }^{*}+$ SADAO IMAIZUMI, ${ }^{1}$ SEIKO MIZUNO, ${ }^{2}$ \\ TSUNEKO BABA, ${ }^{3}$ MICHIO TSUKAMURA ${ }^{4}$ AND IKUYA YANO ${ }^{3}$ \\ ${ }^{1}$ Department of Bacteriology, Niigata University School of Medicine, Asahimachidori 1, \\ Niigata, Japan \\ ${ }^{2}$ Soai Women's College, Osaka, Japan \\ ${ }^{3}$ Department of Bacteriology, School of Medicine, Osaka City University, Asahimachi 1-4-54, \\ Abeno-ku, Osaka, Japan \\ ${ }^{4}$ The National Chubu Hospital, Obu, Aichi, Japan
}

(Received 8 December 1987; revised 15 February 1988)

Three homologous series of $\alpha$-mycolic acids (dicyclopropanoyl acids, monocyclopropanoyl monoenoic acids and dienoic acids) from 16 rapidly growing and 14 slowly growing mycobacteria were separated by argentation thin-layer chromatography and analysed by gas chromatography/mass spectrometry of their trimethylsilyl ether derivatives. Mycobacterial species were separated into five groups. Strains of group A contained similar amounts of even and odd carbon-numbered dienoic acids, with a methyl branch on the odd acids and a $C_{24}-\alpha-$ unit, as typified by Mycobacterium fortuitum and $M$. chitae. Group B strains possessed similar amounts of even carbon-numbered dicyclopropanoyl $\alpha$-mycolic acids and odd carbon-numbered unsaturated acids with $\mathrm{C}_{22^{-}}$and $\mathrm{C}_{24}-\alpha$-units, as found in $M$. phlei and $M$. diernhoferi. Group C strains contained mainly even carbon-numbered dicyclopropanoyl acids with $\mathrm{C}_{22}$ - and $\mathrm{C}_{24}-\alpha$-units, as shown by $M$. vaccae and $M$. aurum. Group D strains possessed mainly odd carbon-numbered dienoic acids with a methyl branch and a $\mathrm{C}_{24}-\alpha-$-unit, as seen in $M$. triviale and $M$. nonchromogenicum. Group $E$ strains had mainly even carbon-numbered dicyclopropanoyl acids with $\mathrm{C}_{24^{-}}$or $\mathrm{C}_{26^{-}} \alpha$-units, as found in $M$. avium and $M$. tuberculosis. Many rapidly growing mycobacteria also produced $\alpha^{\prime}$-mycolic acids which were shorter in the length of the main carbon chain but whose $\alpha$-units were the same as those in $\alpha$-mycolic acids from the same species. These $\alpha^{\prime}$-mycolic acids had either one or two double bonds and showed variations in both their unsaturation and overall size, which may be useful in taxonomic studies.

\section{INTRODUCTION}

The analysis of subclasses of mycolic acids, the most characteristic cell wall component of the acid-fast bacteria, by thin-layer chromatography (TLC) (Daffé et al., 1983) or by twodimensional TLC (Minnikin, 1982; Minnikin et al., 1980, 1984, 1985) has shown that several characteristic patterns are useful for the classification of mycobacteria. As for the structural determination of mycobacterial $\alpha$-mycolic acids, several species such as $M y c o b a c t e r i u m$ phlei (Kusamuran et al., 1972), M. smegmatis (Etémadi et al., 1967), M. chelonae (Minnikin et al., 1982), M. fortuitum (Lacave et al., 1987), M. tuberculosis (Minnikin \& Polgar, 1967),

† Present address: Department of Anatomy, Faculty of Medicine, Tokyo Medical and Dental University, Yushima 1-5-45, Bunkyo-ku, Tokyo 113, Japan.

Abbreviations: $\mathrm{AgNO}_{3}$-TLC, argentation thin-layer chromatography; TMS, trimethylsilyl; mono $\triangle$, monocyclopropane; di $\triangle$, dicyclopropane. 
M. parafortuitum (Lanéelle \& Lanéelle, 1970), M. avium (Lamonica \& Etémadi, 1967), $M$. kansasii (Etémadi, 1967) and M. marianum (scrofulaceum) (Bruneteau \& Michel, 1968) (for a review, see Minnikin, 1982) have been examined by mass spectrometry (MS) of their degradative products after pyrolysis or ozonolysis and by nuclear magnetic resonance spectroscopy. By isolating each molecular species of mycolic acid using high-performance liquid chromatography, $\alpha$-mycolic acids of $M$. smegmatis (Danielson \& Gray, 1982) and $M$. tuberculosis (Qureshi et al., 1978) were successfully analysed for each molecular species using MS. We have clarified the structure and the molecular species composition of $\alpha$-mycolic acids in Nocardia spp., Rhodococcus spp. and Mycobacterium spp., using gas chromatography (GC), GC/MS and mass chromatography. The molecular species composition is characteristic for each species, and GC/MS and mass chromatographic analysis of mycolic acids is very precise and informative (Yano et al., 1978; Toriyama et al., 1978; Kaneda et al., 1986a,b). Three different homologous series of mycobacterial $\alpha$-mycolic acids have been reported, dicyclopropanoyl acids, monocyclopropanoyl monoenoic acids and dienoic acids (Minnikin, 1982; Daffé et al., 1983). In a previous paper on the molecular species composition of 25 mycobacterial species (Kaneda $e t$ $a l ., 1986 b$ ), we did not distinguish cyclopropane rings from double bonds in the main chain portion of $\alpha$-mycolic acids, because the mass spectra of $\alpha$-mycolic acids did not permit this information. In this study, we have differentiated these three homologous series of $\alpha$-mycolic acids in 30 mycobacterial species. Their distribution and molecular species characteristics have been studied using argentation thin-layer chromatography $\left(\mathrm{AgNO}_{3}-\mathrm{TLC}\right), \mathrm{GC} / \mathrm{MS}$ combined with a hydrogenation technique and mass chromatography.

\section{METHODS}

Strains and culture conditions. The following 16 rapidly growing species were studied. Photochromogenic species: $M$. vaccae VA-1 and $M$. parafortuitum PA-1, PA-4, 19686. Scotochromogenic species: $M$. phlei $14002 ; M$. rhodesiae RHO-1; $M$. gilvum GI-1; $M$. duvalii DU-2, 29505; $M$. aurum AU-1; and $M$. thermoresistibile 01028, laboratory strain. Nonchromogenic species: M. chelonae R-1, R-2, 22011 (subsp. abscessus), 19009 (subsp. chelonae); M. smegmatis Takeo, Rabinobitz; $M$. chitae CH-2, CH-3; M. fortuitum F-6, 18001, 18112, E-11592 and E-11620 (subsp. acetamidolyticum); ' $M$. peregrinum' PE-4; $M$. porcinum 19506; $M$. diernhoferi 41002,$41004 ; M$. pulveris 33505; and $M$. agri 90002,90012 . Cultures of the above species were incubated on a shaker at $30^{\circ} \mathrm{C}$ until mid-exponential phase (about 3-5 d) in medium ( $\mathrm{pH} 7.0$ ) containing $1 \%(\mathrm{w} / \mathrm{v}$ ) glucose, $0.5 \%$ peptone and $0.2 \%$ yeast extract, except that $M$. fortuitum subsp. acetamidolyticum was cultured for $7 \mathrm{~d}$ and $M$. thermoresistibile was grown at $37^{\circ} \mathrm{C}$ for $7 \mathrm{~d}$.

The following 14 slow growing species were studied. Photochromogenic species: $M$. kansasii laboratory strain; $M$. marinum 08010; and $M$. simiae 93001 . Scotochromogenic species: $M$. gordonae T-12109. Nonchromogenic species: $M$. terrae $38016 ; M$. nonchromogenicum $09003 ;$ ' $M$. novum' 24018; $M$. triviale 37014; $M$. avium $11016 ; M$. intracellulare 13023; $M$. ulcerans 28504; $M$. shimoidei 43501; $M$. bovis $\mathrm{BCG}$, Ravenel; and $M$. tuberculosis $\mathrm{H}_{37} \mathrm{Rv}$. These cultures were grown for 3-5 weeks at $37^{\circ} \mathrm{C}$ in Sauton medium, pH 7.2 or on slants containing Ogawa egg medium, which contained $100 \mathrm{ml}$ of a basal solution $\left(1 \%, \mathrm{w} / \mathrm{v}\right.$, sodium glutamate and $\left.1 \%, \mathrm{w} / \mathrm{v}, \mathrm{KH}_{2} \mathrm{PO}_{4}\right), 200 \mathrm{ml}$ whole egg, $6 \mathrm{ml}$ glycerol and $6 \mathrm{ml} 2 \%(\mathrm{w} / \mathrm{v})$ malachite green solution.

Preparation of fatty acid methyl esters. Whole cells, harvested by centrifugation, were hydrolysed with $15 \%(\mathrm{w} / \mathrm{v})$ $\mathrm{KOH}$ at $90^{\circ} \mathrm{C}$ for 3-4 h. After acidification with $\mathrm{HCl}$, the fatty acids liberated were extracted with $\mathrm{n}$-hexane and subsequently methylated in 5-10 ml benzene/methanol/concentrated $\mathrm{H}_{2} \mathrm{SO}_{4}\left(10: 20: 1\right.$, by vol.) at $90^{\circ} \mathrm{C}$ for $1.5 \mathrm{~h}$.

TLC and $\mathrm{AgNO}_{3}-\mathrm{TLC}$. The fatty acid methyl esters were developed on a TLC plate of Silica gel G (Analtech) with $n$-hexane/diethyl ether $(4: 1, v / v)$. After locating with iodine vapour each mycolic acid subclass was recovered with chloroform. Isolated $\alpha$-mycolic acid methyl esters were further separated on a $10 \%(\mathrm{w} / \mathrm{v}) \mathrm{AgNO}_{3}-\mathrm{TLC}_{\text {plate }}$ of silica gel $60 \mathrm{G}$ (Merck) with $\mathrm{n}$-hexane/diethyl ether $(94: 6, \mathrm{v} / \mathrm{v})$; this developing procedure was repeated four times. The spots were visualized with charring after being sprayed with $50 \%(\mathrm{v} / \mathrm{v}) \mathrm{H}_{2} \mathrm{SO}_{4}$. For recovery, TLC samples were located with iodine vapour and $\mathrm{AgNO}_{3}$-TLC samples were located with $2^{\prime}, 7^{\prime}$-dichlorofluorescein.

Hydrogenation experiments. $\alpha$-, $\alpha^{\prime}$ - or $\alpha+\alpha^{\prime}$-mycolic acids separated on TLC, or one class of $\alpha$-mycolic acids separated on $\mathrm{AgNO}_{3}$-TLC, were recovered with chloroform and hydrogenated to distinguish double bonds from cyclopropane rings in the molecules; double bonds can be hydrogenated in neutral solvents, whereas cyclopropane rings can be hydrogenated only in acidic solvent systems. The sample was hydrogenated in chloroform/methanol $(2: 1, v / v)$ with a few milligrams of platinum oxide $\left(\mathrm{PtO}_{2}\right.$ : Adams catalyst) for $1 \mathrm{~h}$ at room temperature or in glacial acetic acid for $4 \mathrm{~h}$ at $40^{\circ} \mathrm{C}$ to cleave the cyclopropane rings (Kaneshiro \& Marr, 1961). After removal of the catalyst by filtration, the solvent was evaporated off. 
Preparation of trimethylsilyl (TMS)-ether derivatives of mycolic acid methyl esters. For GC and GC/MS analysis, $\alpha$ - and $\alpha^{\prime}$-mycolic acid methyl esters before or after the hydrogenation were converted to the TMS derivatives, which are stable at high temperatures (Yano et al., 1978; Toriyama et al., 1978). Pyridine (0.1 ml) and bistrimethylsilyl-trifluoroacetamide $(0.2 \mathrm{ml})$ were added to the dried methyl mycolate $(1-5 \mathrm{mg})$ and incubated at $70^{\circ} \mathrm{C}$ for $20 \mathrm{~min}$. The solvent and by-products were evaporated off.

GC, GC/MS and mass chromatographic analysis of the TMS-ether derivatives of mycolic acid methyl esters. The procedure has been described in detail previously (Kaneda et al., 1986 ). TMS derivatives of methyl mycolate were analysed by GC (Hitachi 063 ) with a glass column $(0.4 \mathrm{~m} \times 3 \mathrm{~mm}, 1 \%$ OV-101 on Gaschrom $\mathrm{Q}$, column temperature $330^{\circ} \mathrm{C}$ isothermally) and subsequently by a GC/MS system (Hitachi M-80B) with the same column (the ionization voltage was $20 \mathrm{eV}$ and the accelerating voltage, $3 \mathrm{kV}$ ). The mass spectra were represented as the average value of several scans around the peak top on the chromatograms of the total ion current. Mass chromatograms were obtained by monitoring $[M-15]^{+}$ions of the TMS derivatives of each carbon-number class of mycolic acid methyl esters. On mass chromatograms each molecular species could be shown as an independent peak, and by measuring its peak area the molecular species composition and the average carbon number $[=\Sigma$ (carbon number $\times$ percentage/100)] could be determined. As well as determining the overall size of mycolic acids, the size of the so-called $\mathrm{C}_{22^{-}}, \mathrm{C}_{24^{-}}$and $\mathrm{C}_{26^{-}}-\alpha$-units was determined by mass chromatogram monitoring of ions resulting from cleavage between the second and third carbon in the $\alpha$-mycolic acid derivatives.

\section{RESULTS}

\section{Subclass composition of mycolic acids}

On TLC plates spots corresponding to non-polar fatty acid methyl esters were observed close to the solvent front and below them several spots were seen corresponding to each subclass of mycolic acid methyl ester. $\alpha$-Mycolic acids, the most hydrophobic among all the mycolic acid subclasses, were usually a major component in every mycobacterial species except for $M$. duvalii and $M$. shimoidei, which contained only a trace amount. $\alpha^{\prime}-$ Mycolic acids, whose main carbon chains are shorter than those of $\alpha$-mycolic acids, were present in many rapidly growing species (all except $M$. diernhoferi, $M$. gilvum, $M$. phlei and $M$. rhodesiae) and in two slow growers, $M$. simiae and $M$. shimoidei.

\section{Analysis of $\alpha$-mycolic acids}

$\mathrm{AgNO}_{3}-\mathrm{TLC}$. On $\mathrm{AgNO}_{3}$-TLC, purified $\alpha$-mycolic acid methyl esters both from rapidly and from slowly growing mycobacteria were further separated (Fig. 1). Each consisted of one or two components (upper and lower spots). In the rapid growers $M$. chitae, $M$. fortuitum, $M$. smegmatis and $M$. chelonae, a lower spot predominated but, except for $M$. chitae, they also had a small amount of an upper spot. $M$. rhodesiae, $M$. diernhoferi, $M$. phlei and $M$. parafortuitum contained both upper and lower spots, and $M$. pulveris, $M$. thermoresistibile, $M$. aurum, $M$. vaccae, $M$. gilvum and $M$. agri possessed primarily an upper spot. The slow growers $M$. nonchromogenicum, $M$. terrae, $M$. triviale and ' $M$. novum' possessed mainly a lower spot with a very minor upper component. With the exception of $M$. bovis BCG, which also contained a smaller amount of a lower spot, $M$. tuberculosis, $M$. kansasii, $M$. simiae, $M$. marinum, $M$. gordonae, $M$. avium, $M$. intracellulare and $M$. ulcerans contained only an upper spot.

$G C$. The gas chromatograms of $\alpha$-mycolic acid derivatives gave generally well-separated peaks ranging from $C_{70}$ to $C_{82}$ in rapid growers (Fig. 2) and from $C_{72}$ to $C_{86}$ in slow growers (Kaneda et al., 1986 b). The carbon number of the $\alpha$-mycolic acids in each peak was determined from its mass spectrum as described later. The $\alpha$-mycolates from $M$. parafortuitum, $M$. rhodesiae, $M$. phlei and $M$. diernhoferi, however, showed gas chromatographic profiles with poorly separated peaks, probably due to a higher content of odd carbon-numbered acids.

$G C / M S$. The structure of the molecular species of $\alpha$-mycolic acids separated by GC was determined from the mass spectra. From the mass number of the characteristic fragment ions of the TMS methyl $\alpha$-mycolate, i.e. $[\mathrm{M}]^{+}$(molecular ion), $[\mathrm{M}-15]^{+}\left(\right.$loss of $\left.-\mathrm{CH}_{3}\right),[\mathrm{M}-90]^{+}($loss of trimethylsilanol), [A] $]^{+}$(TMS-alkoxy ion resulting from $\mathrm{C}_{2}-\mathrm{C}_{3}$ cleavage), [A-90] ${ }^{+}$(loss of trimethylsilanol from $\left.[\mathrm{A}]^{+}\right),[\mathrm{B}]^{+}$(TMS-oxymethylene carboxylic acid ester resulting from $\mathrm{C}_{3}-\mathrm{C}_{4}$ cleavage) and $[\mathrm{B}-29]^{+}$(loss of $\mathrm{CHO}$ from $[\mathrm{B}]^{+}$), the numbers of carbons and double bonds (or cyclopropane rings) of the whole molecule $\left[\mathrm{RCH}(\mathrm{OH}) \mathrm{CH}\left(\mathrm{R}^{\prime}\right) \mathrm{COOH}\right.$, the $\beta$-unit 
(a)
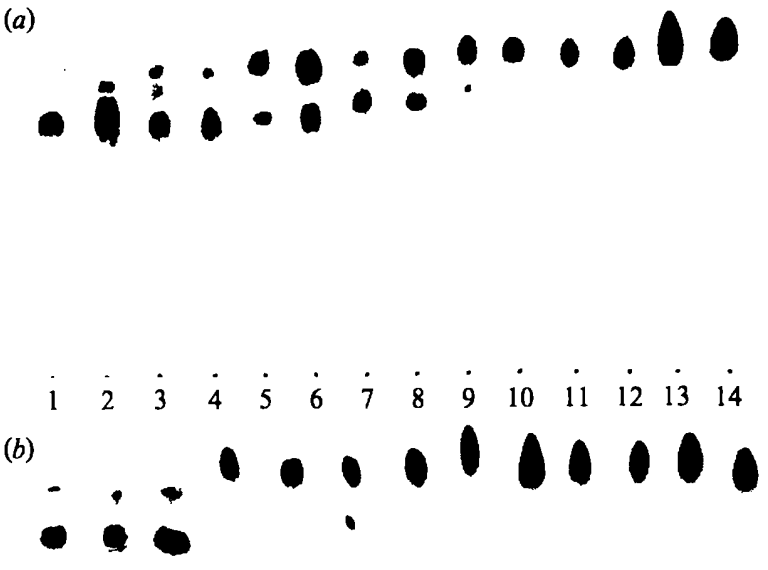

Fig. 1. $\mathrm{AgNO}_{3}(10 \% \mathrm{v} / \mathrm{v})$-TLC of $\alpha$-mycolic acid methyl esters from rapidly growing mycobacteria $(a)$ and slowly growing mycobacteria $(b)$. Chromatograms were developed four times with $\mathrm{n}$-hexane/ diethyl ether $(94: 6, \mathrm{v} / \mathrm{v})$. (a) Lanes: $1, M$. chitae $\mathrm{CH}-2 ; 2, M$. fortuitum 18112; 3, M. smegmatis Takeo; 4, M. chelonae R-1; 5, M. rhodesiae RHO-1; 6, M. diernhoferi 41002; 7, M. phlei 14002; 8, M. parafortuitum PA-1 ; 9, M. thermoresistibile Lab.; 10, M. pulveris 33505; 11, M. vaccae VA-1; 12, M. aurum AU-1; 13, M. gilvum GI-1; 14, $M$. agri 90012 . (b) Lanes: 1 , 'M. novum' 24020;2, $M$. triviale 37014; 3, $M$. terrae $38021 ; 4, M$. tuberculosis $\mathrm{H}_{37} \mathrm{Rv} ; 5, M$. bovis Ravenel; 6, M. bovis BCG; 7, M. kansasii Lab.; 8, $M$. simiae $93001 ; 9, M$. marinum $08010 ; 10, M$. gordonae T-12109; $11, M$. intracellulare $13542 ; 12, M$. avium 11016; 13, M. ulcerans 28504.

[RCH(OH)] and the $\alpha$-unit $\left[\mathrm{CH}\left(\mathrm{R}^{\prime}\right) \mathrm{COOH}\right]$ could be determined. For example, the mass spectrum of one major GC peak of $\alpha$-mycolic acids in $M$. vaccae (Fig. 3) showed [M] ${ }^{+}=1194$, $[M-15]^{+}=1179$ and $[M-90]^{+}=1104$, which corresponded to $C_{76^{-}} \alpha$-mycolic acids with two double bonds (or cyclopropane rings) $[\mathrm{A}]^{+}=841,813$ and $[\mathrm{B}]^{+}=455,483$, indicating that these

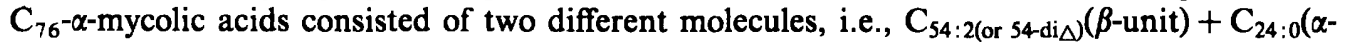
unit) and $\mathrm{C}_{52: 2(\text { or } 52-\mathrm{di} \Delta}\left(\beta\right.$-unit) $+\mathrm{C}_{24: 0}(\alpha$-unit). In every mycobacterial species, $\alpha$-mycolic acids possessed two double bonds (or the equivalent in cyclopropane rings). A double bond and a cyclopropane ring in $\alpha$-mycolic acids could not be differentiated from each other by the mass spectrum only, because dicyclopropanoyl $\alpha$-mycolic acid derivatives showed mass numbers equivalent to the dienoic species.

GC or GC/MS analysis combined with the hydrogenation technique. To clarify whether the $\beta$-unit of the $\alpha$-mycolic acids possessed a cyclopropane ring or a double bond, we combined GC or GC/MS analysis with the hydrogenation technique. When the $\alpha$-mycolic acid derivatives of $M$. chitae, which showed only a lower spot on $\mathrm{AgNO}_{3}$-TLC (Fig. 1), were analysed after hydrogenation in neutral solvents the retention time of the GC peak became longer by about $0 \cdot 7$ carbon numbers and the mass spectral $[M-15]^{+}$and $[A]^{+}$ions increased by four mass units, showing that these $\alpha$-mycolic acids were dienoic and that they received four hydrogens to become saturated acids (Fig. 3). On the other hand, when $\alpha$-mycolic acid derivatives of $M$. vaccae, which showed only an upper spot on AgNO-TLC (Fig. 1), were hydrogenated in the neutral solvent, no change was observed. After hydrogenation in the acidic solvent, however, 


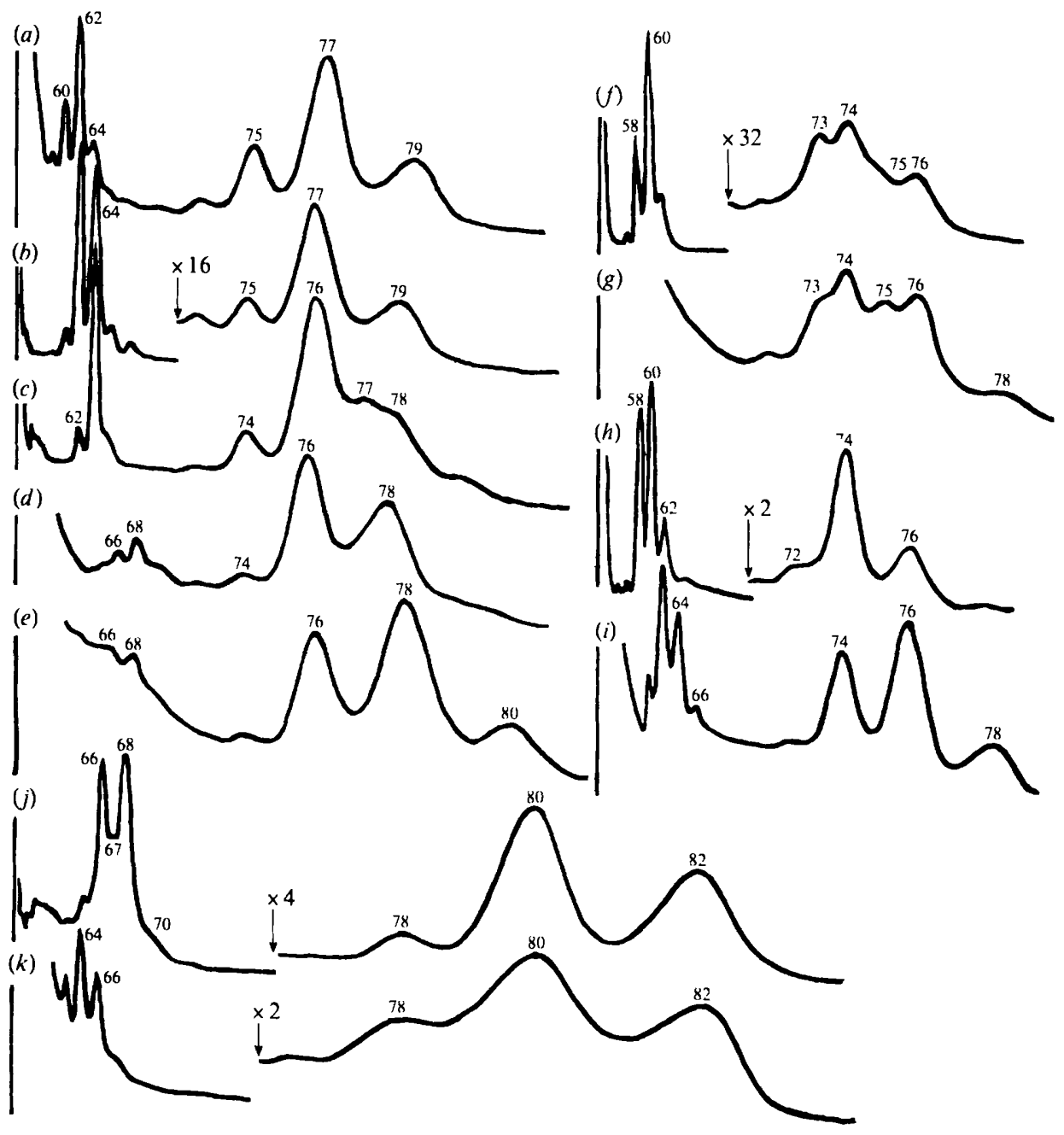

Fig. 2. Gas chromatograms of TMS-ether derivatives of $\alpha^{\prime}$ - and $\alpha$-mycolic acid methyl esters from rapidly growing mycobacteria, showing characteristic profiles. The carbon numbers of the esters in each peak were determined from the mass spectra. (a), M. chitae $\mathrm{CH}-2 ;(b), M$. smegmatis Rabinovitz; (c), M. chelonae R-2; (d), M. fortuitum F-6; (e), M. fortuitum subsp. acetamidolyticum E-11620; $(f), M$. parafortuitum PA-4; $(g)$, M. rhodesiae RHO-1; (h), M. vaccae VA-1; (i), M. aurum AU-1; $(j), M$. agri 90002; $(k), M$. thermoresistibile Lab.

the retention time of the GC peak became shorter by about 1.5 carbon numbers and its mass number of $[M-15]^{+}$and $[A]^{+}$increased by four mass units with no change in the mass number of $[\mathrm{B}]^{+}$, showing that the $\alpha$-mycolic acids were dicyclopropanoyl and that they received four hydrogens in the acidic solvent to cleave cyclopropane rings and to become dimethyl branched saturated acids (Fig. 3). For $M$. phlei, which showed two spots, upper and lower, on $\mathrm{AgNO}_{3}$ TLC (Fig. 1), we examined the $\alpha$-mycolic acids of each spot by mass spectrometry after hydrogenation in the neutral solvent. Derivatives of the $\alpha$-mycolic acids in the upper spot showed no change, indicating that they were dicyclopropanoyl acids, but the mass spectral $[\mathrm{M}-15]^{+}$and $[\mathrm{A}]^{+}$ions from the lower spot increased by two mass units, indicating that they were monocyclopropanoyl monoenoic acids (the lower spot also contained a small amount of dienoic acids as indicated by coexistence of a slightly higher intensity mass spectral $[\mathrm{A}]^{+}$ion increased by four mass units) (Fig. 4). In $M$. diernhoferi, $M$, rhodesiae and $M$. parafortuitum, the 

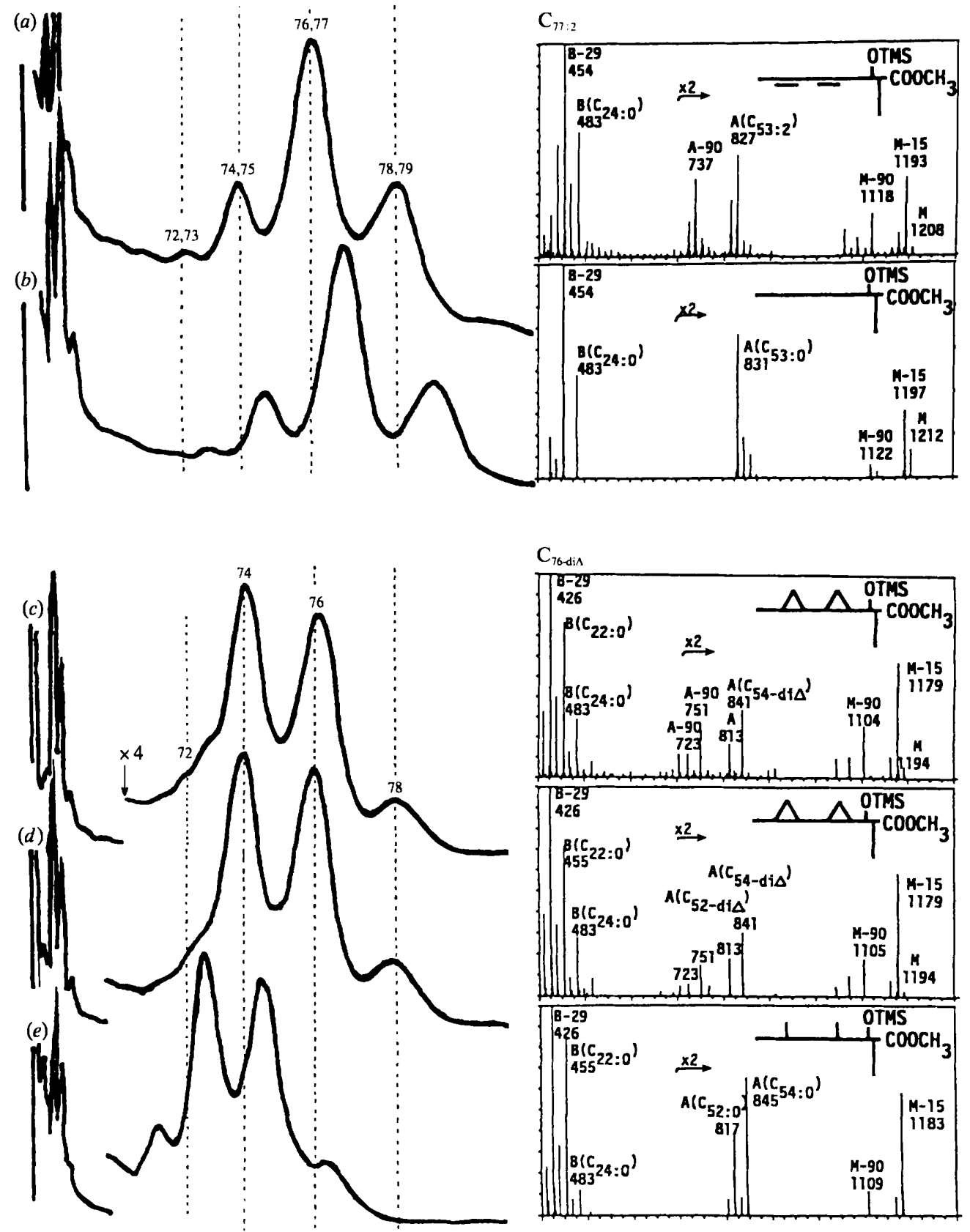

Fig. 3. Gas chromatograms and mass spectra of the main GC peak with the corresponding carbon skeleton structure of $\alpha$-mycolic acid derivatives from $M$. chitae $\mathrm{CH}-2(a, b)$ and $M$. vaccae VA-1 $(c-e)$ before hydrogenation $(a, c)$ after hydrogenation in chloroform/methanol $(b, d)$ or after hydrogenation in glacial acetic acid (e).

upper spots on $\mathrm{AgNO}_{3}$-TLC were also shown to be dicyclopropanoyl $\alpha$-mycolates and the lower spots to be composed of similar amounts of dienoic and monocyclopropanoyl monoenoic acid derivatives from the two strong $[M-15]^{+}$ions with increases of two and four mass units after hydrogenation in the neutral solvent (data not shown). The upper spots in most slow growers 

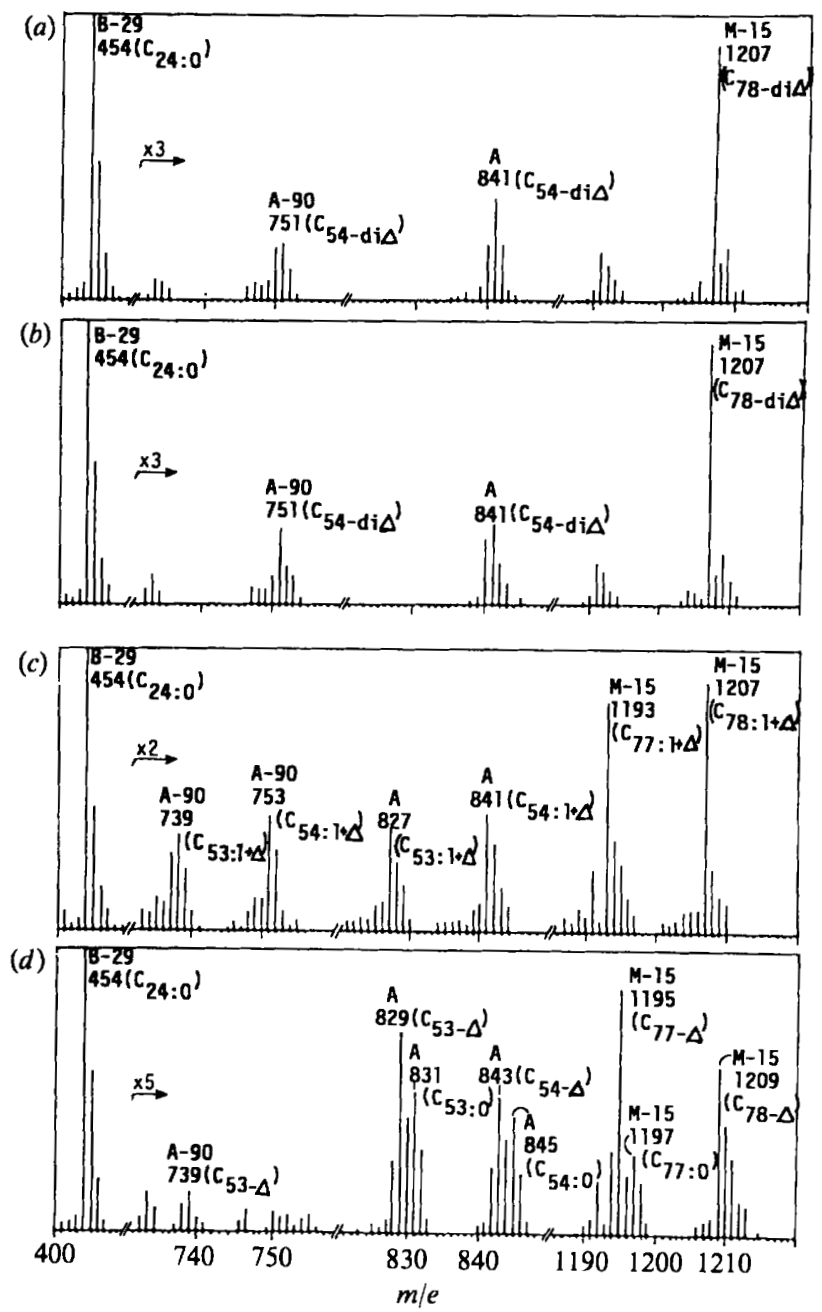

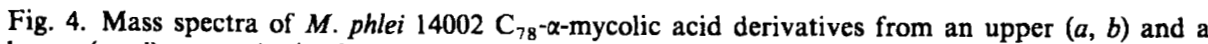
lower $(c, d)$ spot obtained on $\mathrm{AgNO}_{3}$-TLC, before $(a, c)$ and after $(b, d)$ hydrogenation in chloroform/methanol.

(Fig. 1) were shown to be dicyclopropanoyl acid derivatives and the lower spots in the $M$. nonchromogenicum complex which includes ' $M$. novum', $M$. terrae and $M$. triviale (Fig. 1) to be dienoates. $M$. bovis BCG, exceptionally, contained a small amount of dienoic $\alpha$-mycolates (lower spot) (Fig. 1) in addition to the major dicyclopropanoyl species (upper spot).

Mass chromatography. Since the gas chromatographic peaks of mycobacterial $\alpha$-mycolic acid derivatives tended to overlap with their neighbours due to their relative broadness and the relatively high contents of odd carbon-numbered acids (as described later), the molecular species composition of $\alpha$-mycolic acids was determined by measuring the area of each peak shown independently on a mass chromatogram which monitored the mass number of $[M-15]^{+}$ions of each carbon-number class of diunsaturated $\alpha$-mycolic acids (Fig. 5). Data on the molecular species composition of $\alpha$-mycolic acids obtained by this method and the average carbon number in representative mycobacterial species were reported previously (Kaneda et al., 1986b). There was a marked specificity in the distribution of $\alpha$-mycolic acid molecular species among the mycobacteria. For example, the main peak of $\alpha$-mycolic acids was $C_{74}$ in $M$. vaccae, $M$. parafortuium, etc., $\mathrm{C}_{76}$ in $M$. fortuitum, $M$. aurum, etc., $\mathrm{C}_{77}$ in $M$. chitae, $M$. nonchromogenicum, 


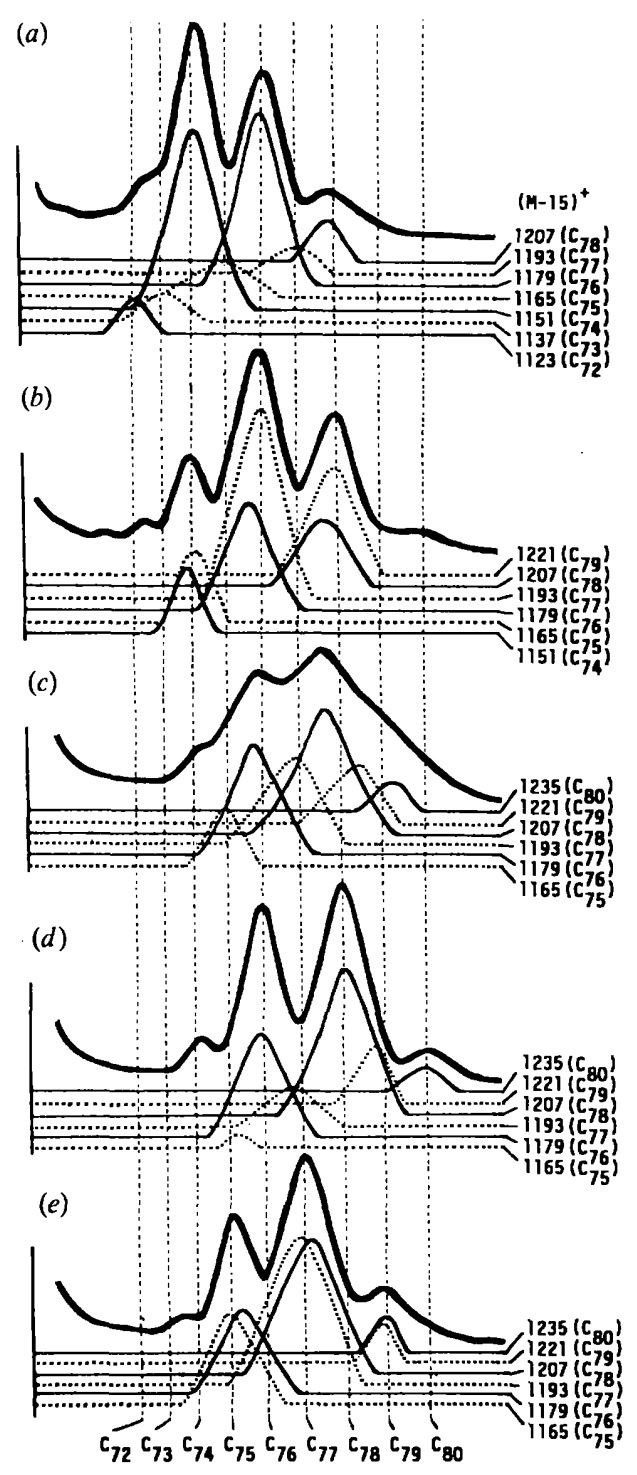

Fig. 5. Mass chromatograms of total (upper + lower spots) $\alpha$-mycolic acid derivatives from $M$. vaccae VA-1 $(a), M$. chitae CH-2 $(b)$ and $M$. phlei $14002(c)$, the components of the upper $(d)$ and lower $(e)$ spots on $\mathrm{AgNO}_{3}$-TLC from the mycolates of the latter strain are also shown. The mass numbers shown on the right correspond to the $[M-15]^{+}$ions of TMS-ether derivatives of the dienoic or dicyclopropanoyl $\alpha-$ mycolic acid methyl esters whose carbon numbers are given in parentheses. The thick solid line is the gas chromatogram. Thin solid lines and dotted lines are mass chromatograms of even and odd carbonnumbered acid derivatives, respectively. The carbon numbers $\mathrm{C}_{72}-\mathrm{C}_{80}$, shown at the bottom of the figure indicate the relative retention of each unbranched dienoic or dicyclopropanoyl $\alpha$-mycolic acid.

etc., $\mathrm{C}_{78}$ in $M$. gilvum, $M$. bovis, etc., $\mathrm{C}_{79}$ in $M$. terrae, $M$. triviale, etc. and $\mathrm{C}_{80}$ in $M$. agri, $M$. tuberculosis, etc. The molecular species composition of a given mycobacterial species did not vary significantly as long as the growth conditions did not change. The proportion of even carbon-numbered acids was characteristic to each species and was conveniently divided into three groups. (1) Even acids up to $30 \%$ : M. terrae $38016^{*}(25 \cdot 2 \%)$; M. nonchromogenicum $09003^{*}$ $(26.0 \%)$; 'M. novum' $24018^{*}(27.0 \%)$. (2) Even acids from 30 to $70 \%$ : $M$. smegmatis Jucho.* $(32.4 \%)$; M. chitae CH-2 (37.3\%); M. chelonae $19009^{*}(48.9 \%) ;$ M. rhodesiae RHO-1* (50.1\%); 
M. phlei $14002(57.8 \%)$; M. fortuitum 18001* (58.1\%); M. parafortuitum PA-1 (61.1\%); $M$. diernhoferi $41002(67.1 \%)$. (3) Even acids more than $70 \%$ : M. bovis BCG (72.7\%); M. marinum $08010^{*}(73.0 \%) ; M$. pulveris $33505(73.6 \%)$; M. vaccae VA-1 (76.4\%); M. tuberculosis $\mathrm{H}_{37} \mathrm{Rv}^{*}$ $(77.4 \%) ; M$. agri $90012 *(81.3 \%) ; M$. avium $11016 *(82.0 \%) ; M$. intracellulare $13023 *(82.0 \%)$; $M$. bovis Ravenel* $(82.0 \%) ; M$. thermoresistibile Lab.* $(82.3 \%) ; M$. aurum AU-1* $(86.0 \%) ; M$. gordonae T-12109* (87.5\%); M. gilvum GI-1 (89.0\%); M. ulcerans $28504(89.5 \%)$; and $M$. kansasii Lab.* $(94 \cdot 3 \%)$. [The values for the species with an asterisk were calculated from the data in our previous paper (Kaneda et al., 1986b); the remaining species were newly examined or reexamined in this study.]

Mass chromatograms, monitoring [M-15]+ ions of $\alpha$-mycolic acids of $M$. vaccae and $M$. chitae, showed that the retention time of the odd carbon-numbered acids differed between these two species; in $M$. vaccae, odd acids came essentially between the even acids, whereas in $M$. chitae, odd acids appeared close to the retention time of an even acid derivative with one carbon less (Fig. 5). Considering the data on the $\alpha$-mycolic acids of $M$. smegmatis (Danielson \& Gray, 1982), which shows a similar pattern to $M$. chitae, and the fact that the methyl-branched-chain fatty acids appear just after the non-branched-chain parent fatty acids on the gas chromatograms, we believe that the latter type of odd carbon-numbered $\alpha$-mycolic acids possesses one methyl branch on the straight alkyl portion ( $\beta$-unit).

We further examined the mass chromatograms of $\alpha$-mycolic acid derivatives from an upper spot (dicyclopropanoyl acids) and a lower spot (unsaturated acids) when there were two spots on $\mathrm{AgNO}_{3}$-TLC (Fig. 1), as in $M$. phlei (Fig. 5). There was a significant difference between these two spots not only in the chemical structure but also in the molecular species composition. In $M$. phlei, dicyclopropanoyl $\alpha$-mycolic acids were composed mainly of even carbon-numbered acids and the odd acids appeared between the even acids on the mass chromatograms, indicating that there was no methyl branch on the $\beta$-unit. The unsaturated acids (mainly monocyclopropanoyl monoenoic acids as revealed by the hydrogenation experiment) were composed of similar amounts of even and odd acids, and, from the similar retention time of the even acid derivatives to those of the odd acid derivatives with one carbon less, the even acids possessed one methyl branch on the $\beta$-unit. The dicyclopropanoyl and unsaturated acids were distributed within a similar carbon number range, and their average carbon numbers were also similar (Table 1). The molecular species composition and the existence of a methyl branch on the $\beta$-unit was also determined for other mycobacterial species which showed two spots for their mycolate derivatives on $\mathrm{AgNO}_{3}$-TLC (Table 1). Mycobacterial dicyclopropanoyl $\alpha$-mycolic acids were generally non-methyl-branched and consisted mainly of even acids; the proportion of even acids was $76.4 \%$ in $M$. vaccae VA-1, $76.5 \%$ in $M$. phlei and $82.2 \%$ in $M$. bovis BCG. On the other hand, the unsaturated acids (dienoic acids and/or monocyclopropanoyl monoenoic acids) consisted mainly of odd acids (the proportion of even acids was $21 \cdot 1 \%$ in $M$. parafortuitum PA-1, $20 \cdot 1 \%$ in $M$. diernhoferi 41002 , and less than $30 \%$ in the $M$. nonchromogenicum complex) or of a similar amount of even and odd acids (the proportion of even acids was $46.7 \%$ in $M$. phlei 14002 and $37.3 \%$ in $M$. chitae $\mathrm{CH}-2)$, often possessing one methyl branch on the $\beta$-unit of the even acids $(M$. parafortuitum and $M$. phlei) or on that of odd acids (M. chitae, $M$. smegmatis, $M$. fortuitum and the $M$. nonchromogenicum complex) (Table 1). In the case of mycobacterial species which possessed a similar amount of both even acid-dominated dicyclopropanoyl acids and odd acid-dominated unsaturated acids, as in $M$. phlei, $M$. parafortuitum, $M$. diernhoferi and $M$. rhodesiae, the proportion of even carbon-numbered $\alpha$-mycolic acids amounted to $40-60 \%$.

From the mass spectra of each molecular species (Fig. 3) or from mass chromatogram monitoring of [B - 29] $]^{+}$ions $(426,454$ and 482) the sizes of the chains in the $\alpha$-position of the $\alpha$ mycolic acids could be determined. Mycobacterial species were grouped according to whether the $\alpha$-unit was $C_{22}, C_{24}$ or $C_{26}$. (1) Mycolic acids with essentially a $C_{22}-\alpha$-unit: $M$. parafortuitum and $M$. diernhoferi. (2) Mycolic acids with $\mathrm{C}_{22}$ and $\mathrm{C}_{24}-\alpha$-units: $M$. phlei, $M$. rhodesiae, $M$. gilvum, $M$. vaccae, $M$. aurum, $M$. pulveris and $M$. duvalii. (3) Mycolic acids with essentially a $\mathrm{C}_{24^{-}}$ $\alpha$-unit: $M$. chelonae, $M$. smegmatis, $M$. chitae, $M$. fortuitum, ' $M$. peregrinum', $M$. porcinum, $M$. thermoresistibile, $M$. agri, $M$. terrae, $M$. nonchromogenicum, ' $M$. novum', $M$. triviale, $M$. avium, $M$. intracellulare, $M$. kansasii, $M$. marinum, $M$. gordonae, $M$. ulcerans and $M$. shimoidei. (4) Mycolic acids with a $\mathrm{C}_{26}-\alpha$-unit: $M$. simiae, $M$. bovis and $M$. tuberculosis. 


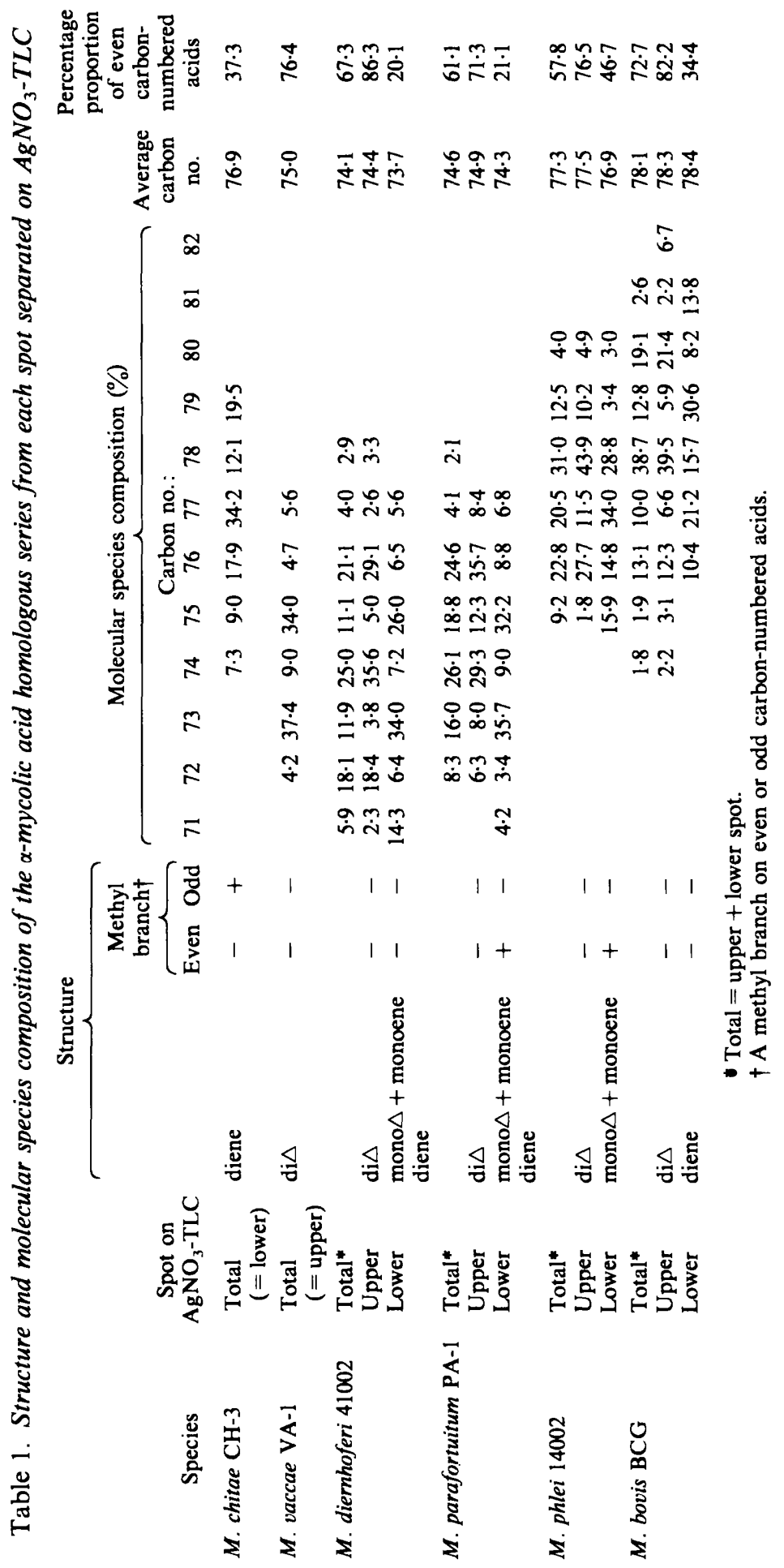




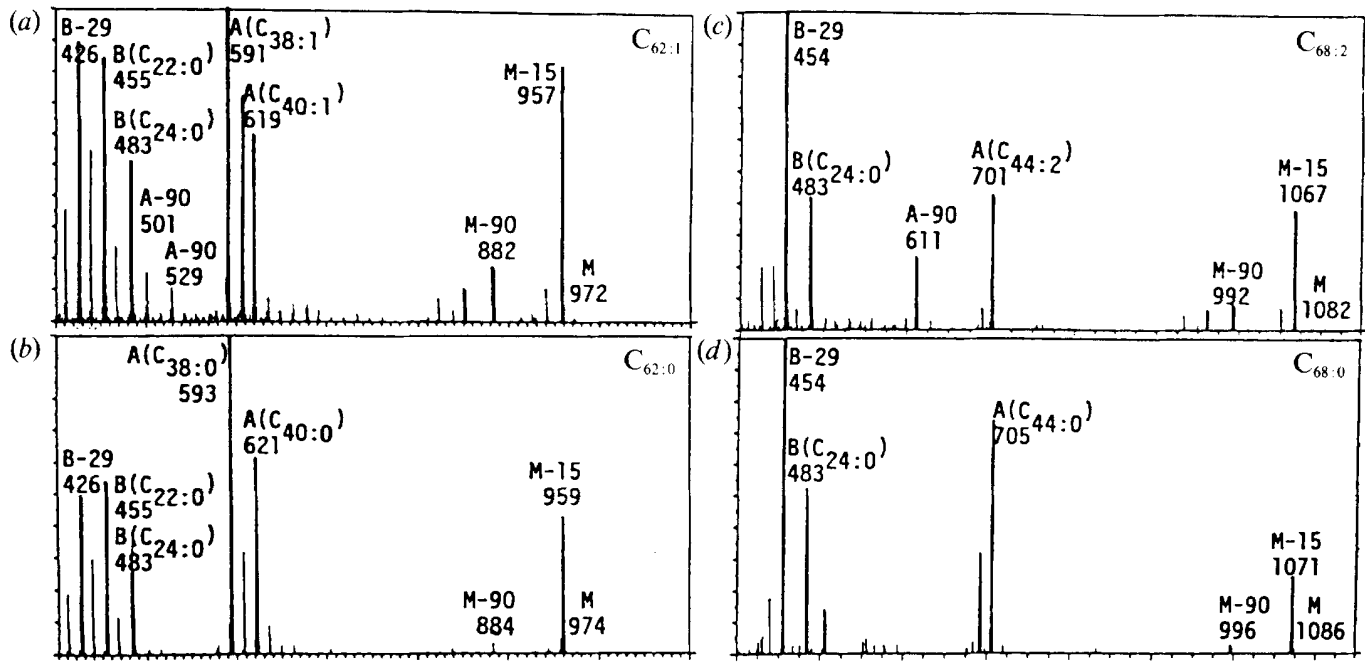

Fig. 6. Mass spectra of the main peaks of $\alpha^{\prime}$-mycolic acid derivatives from $M$. vaccae VA-1 $(a, b)$ and $M$. fortuitum $18001(c, d)$ before $(a, c)$ and after $(b, d)$ hydrogenation in chloroform/methanol.

Analysis of $\alpha^{\prime}$-mycolic acids

Several peaks of $\alpha^{\prime}$-mycolic acid derivatives with sizes ranging from $\mathrm{C}_{58}$ to $\mathrm{C}_{70}$ were clearly observed on gas chromatograms (Fig. 2). In $M$. vaccae, the mass spectrum of the main peak showed: $[\mathrm{M}]^{+}=972,[\mathrm{M}-15]^{+}=957$ and $[\mathrm{M}-90]^{+}=882$, which corresponded to $\mathrm{C}_{62}{ }^{-} \alpha^{\prime}-$ mycolic acids with one double bond (or a cyclopropane ring); $[\mathrm{A}]^{+}=619,591$ and $[\mathrm{B}]^{+}=455$, 483 , indicating that these $\mathrm{C}_{62}-\alpha^{\prime}$-mycolic acids contained $\mathrm{C}_{40: 1 \text { (or } 40 \text {-mono } \Delta)}(\beta$-unit $)+\mathrm{C}_{22: 0}(\alpha$-unit) and $\mathrm{C}_{38: 1(\text { or 38-mono } \Delta)}\left(\beta\right.$-unit) $+\mathrm{C}_{24: 0}(\alpha$-unit) (Fig. 6). In $M$. fortuitum the main component was

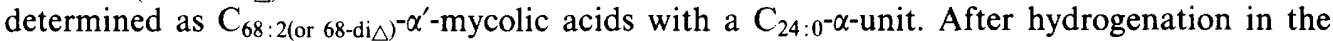
neutral solvent, the $\alpha^{\prime}$-mycolic acids both of $M$. vaccae and of $M$. fortuitum showed mass numbers equivalent to those of the saturated acids, indicating that these two $\alpha^{\prime}$-mycolic acids were monoenoic and dienoic, respectively (Fig. 6). In this study, $\alpha^{\prime}$-mycolic acids of every mycobacterial species were shown to have one double bond except in $M$. fortuitum and related taxa ( $M$. fortuitum subsp. acetamidolyticum, ' $M$. peregrinum' and $M$. porcinum), which possessed two double bonds. Although the $\mathrm{C}_{66,68} \alpha^{\prime}$-mycolic acids of $M$. smegmatis, as reported by Etémadi et al. (1967), and the $\mathrm{C}_{66}{ }^{-\alpha^{\prime}}$-mycolic acids of $M$. chelonae consisted of a significant amount of dienoic acids as revealed by mass chromatography monitoring the $[M-15]^{+}$ions of both dienoic and monoenoic $\alpha^{\prime}$-mycolic acids (data not shown), these dienoic acids only made up a small proportion of the total $\alpha^{\prime}$-mycolic acids. Furthermore, these monoenoic or dienoic $\alpha^{\prime}$ mycolic acids did not have a methyl branch on their $\beta$-unit (deduced from the fact that the odd carbon-numbered acids were always situated between even acids on the mass chromatograms produced by monitoring $[\mathrm{M}-15]^{+}$ions). From the mass chromatograms of $\alpha^{\prime}$-mycolic acids monitoring $[\mathrm{B}-29]^{+}$ions of $\mathrm{C}_{22^{-}}, \mathrm{C}_{24^{-}}$and $\mathrm{C}_{26^{-}}-\alpha$-unit-containing mycolic acids, the proportions of these three homologous series of $\alpha^{\prime}$-mycolic acids were shown to be similar to those of the $\alpha$-mycolic acids from the same bacterial species.

The molecular species composition of $\alpha^{\prime}$-mycolic acids was determined by measuring each peak area on gas chromatograms or mass chromatograms, and the average carbon number was calculated (Table 2). The average carbon number of $\alpha^{\prime}$-mycolic acids varied from species to species; it was about 60 in $M$. parafortuitum and $M$. vaccae, about 62 in $M$. chitae, $M$. duvalii, $M$. aurum and $M$. pulveris, about 64 in $M$. smegmatis, $M$. chelonae, $M$. shimoidei and $M$. thermoresistibile, about 66 in $M$. simiae and about 68 in $M$. fortuitum, $M$. fortuitum subsp. acetamidolyticum, 'M. peregrinum' and $M$. agri. Mass chromatographic analysis revealed that $\alpha$ mycolic acids from every mycobacterial species were composed mainly of even carbon- 


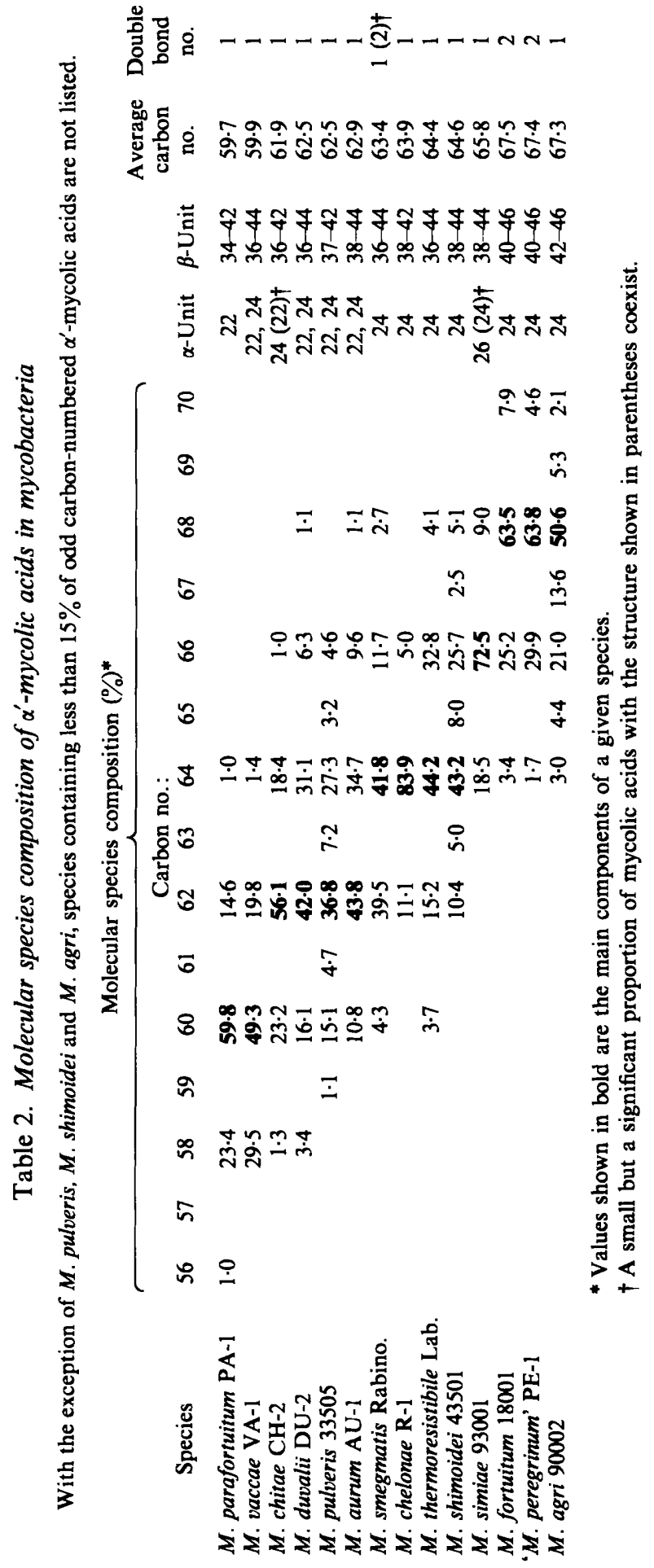


numbered acids. The proportion of odd carbon-numbered $\alpha^{\prime}$-mycolic acids was generally up to about $20 \%$ except in $M$. agri: $M$. vaccae VA-1 and $M$. fortuitum 18001 (trace amount); $M$. simiae 93001 (6.5\%); M. chelonae 22011 (7.8\%); M. chitae $\mathrm{CH}-3$ (8.2\%); M. duvalii 29506 (9.7\%); $M$. parafortuitum PA-1 $(9.8 \%)$; $M$. smegmatis Rabinovitz $(11.3 \%)$; $M$. thermoresistibile Lab. (11.3\%); M. shimoidei 43501 (15.5\%); M. pulveris $33505(16 \cdot 2 \%)$ and M. agri $90002(23 \cdot 3 \%)$.

Variation in the structure and the molecular species composition of $\alpha$-mycolic acids from 16 rapid growers and 14 slow growers allows mycobacterial species to be divided into five groups, A-E, as indicated in Table 3.

\section{DISCUSSION}

Mycobacterial $\alpha$-mycolic acids possess two dicyclopropanoyl rings, one cyclopropane ring plus one double bond or two double bonds on the $\beta$-unit (Minnikin, 1982; Daffé et al., 1983). These three different homologous series of $\alpha$-mycolic acids were identified from the mass ion shift after hydrogenation in neutral or acidic solvents. The upper spot on $\mathrm{AgNO}_{3}$-TLC was shown to be dicyclopropane and the lower one was olefinic acid derivatives - monocyclopropanoyl monoenoic acids and/or dienoic acids. It is uncertain why the latter two homologous series of $\alpha$-mycolic acids could not be clearly separated on $\mathrm{AgNO}_{3}-\mathrm{TLC}$. However, Minnikin (1982) reported that one of the two double bonds on the odd carbon-numbered, mono-methyl branched (or monocyclopropanoyl) $\alpha$-mycolic acids were not cis monoenoic but trans monoenoic. Since it is well known that trans monoenoic fatty acids migrate between the saturated and the cis monounsaturated acids on $\mathrm{AgNO}_{3}$-TLC, $\alpha$-mycolic acids may also behave similarly. In this study, by examining the $\alpha$-mycolic acids of each upper and lower spot on $\mathrm{AgNO}_{3}$-TLC, it was clearly shown that a significant difference existed in the molecular species composition between the dicyclopropanoyl acids and the olefinic acids. Dicyclopropanoyl $\alpha$-mycolic acids were composed mainly of even carbon-numbered acids and possessed no methyl branch on the $\beta$-unit, whereas olefinic acids were composed either of predominantly odd carbon-numbered acids or of a similar amount of odd and even carbon-numbered acids, often possessing one methyl branch on the $\beta$-unit. The result obtained here (that a methyl branch often existed in the $\alpha$-mycolic acids, possessing one or two double bonds) is in accordance with the structural formula of $\alpha$-mycolic acids presented by Minnikin et al. (1984). This is reasonable because a methyl branch is considered to be introduced on the adjacent carbon of a double bond during its cis to trans conversion (Minnikin, 1982).

Many rapid growers produce $\alpha^{\prime}$-mycolic acids which have shorter main chain $\beta$-units than those in the $\alpha$-mycolic acids. In the slow growers, only two species (M. shimoidei and $M$. simiae) contained this type of mycolic acid subclass. However, there was no difference in the structure or the composition of the $\alpha^{\prime}$-mycolic acids from rapid growers and those from slow growers. The $\alpha^{\prime}-$ mycolic acids of $\boldsymbol{M}$. fortuitum and related taxa were characteristically dienoic, whereas in many other species they were monoenoic. These $\alpha^{\prime}$-mycolic acids, both monoenoic and dienoic, possessed no methyl branch on the $\beta$-unit and contained only a small amount of odd carbonnumbered acids ( $M$. agri, $M$. shimoide $i$ and $M$. pulveris possessed relatively more odd carbonnumbered acids, but always less than $30 \%$ of the total $\alpha^{\prime}$-mycolic acids). The carbon chain length of $\alpha^{\prime}$-mycolic acids in groups $B$ and $C$ was generally shorter (up to $\mathrm{C}_{62}$ ) than in group $A$ (more than $\mathrm{C}_{64}$ ).

It has been shown that $\alpha^{\prime}$-mycolic acids are not merely small forms of $\alpha$-mycolic acids, but have rather independent structures, e.g. (1) in groups B and $C$, the $\alpha^{\prime}$-mycolic acids were monoenoic, whereas the $\alpha$-mycolic acids were mainly dicyclopropanoyl derivatives; (2) in group $A$, the odd carbon-numbered $\alpha$-mycolic acids were methyl-branched, but the $\alpha^{\prime}$-mycolic acids were not; (3) the proportions of odd carbon-numbered acids were very low in $\alpha^{\prime}$-mycolic acids; and (4) there were no obvious correlations in the carbon chain length between $\alpha$-and $\alpha^{\prime}$-mycolic acids within the same bacterial species - M. chitae, $M$. smegmatis and $M$. thermoresistibile, which contained longer $\alpha$-mycolic acids $\left(C_{77-80}\right)$, possessed shorter $\alpha^{\prime}$-mycolic acids $\left(C_{62-64}\right)$ and, conversely, $M$. fortuitum and ' $M$. peregrinum', which possessed intermediate sized $\alpha$-mycolic 

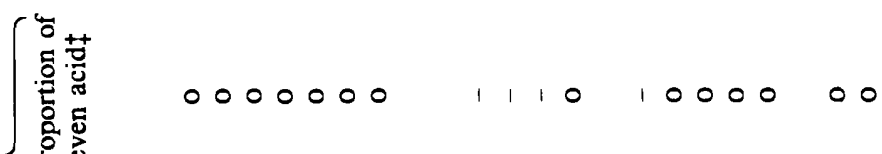

曼鄫

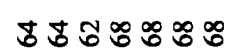

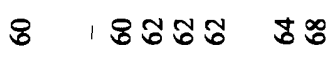

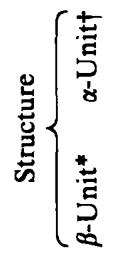

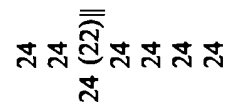

促

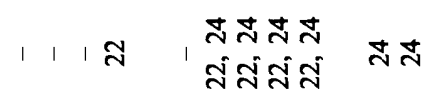

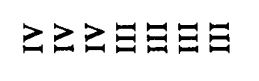

1 1 1 $\geq \quad 1 \geq \geq \geq \geq \quad \geq \geq$

(

$x \times x \times x \times$

$x x x$

$0000 \frac{2}{2}$

$\circ \circ$

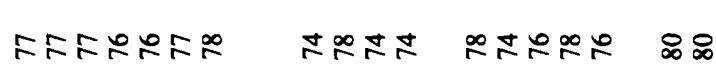

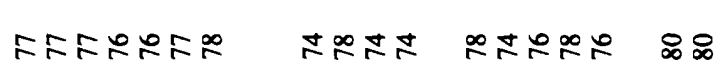

官当

互

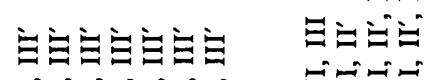

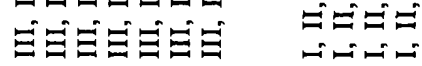

ก

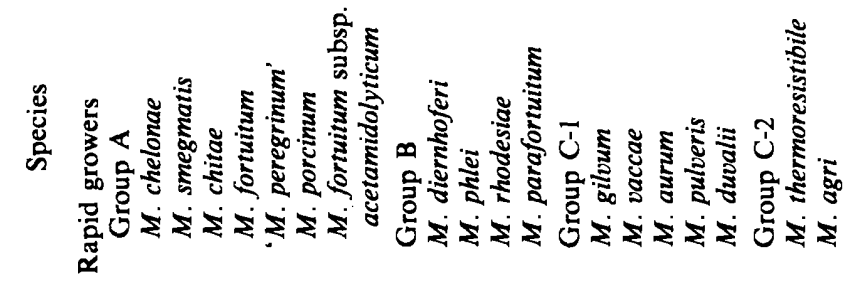


$z z z z \quad z z$ an a $z z$ a z z

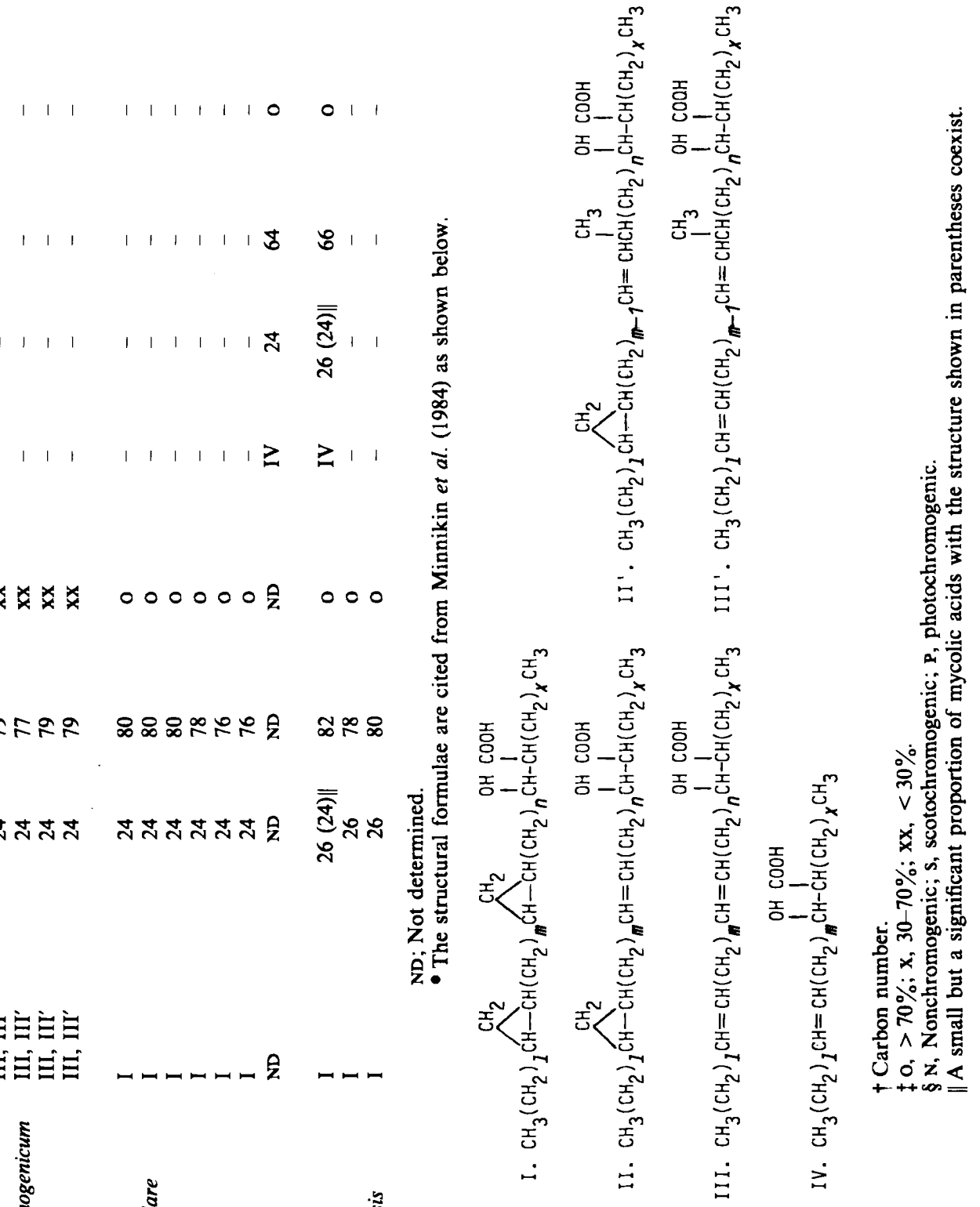


acids $\left(C_{76}\right)$, contained longer $\alpha^{\prime}$-mycolic acids $\left(C_{68}\right)$. The proportions of the $C_{22}$-and $C_{24}-\alpha$-units were, however, similar between the $\alpha$-and $\alpha^{\prime}$-mycolic acids from the same bacterial species. The compositions of the $\alpha$-units in the mycolic acids analysed here (Table 3 ) are in good agreement with the results obtained by pyrolysis gas chromatography (Kusaka \& Mori, 1986).

Chromogenicity can be used to divide rapid growers into two groups. The chromogenic species include many saprophytic mycobacteria isolated from soil or water and the nonchromogens may include several opportunistic pathogens such as $M$. fortuitum and $M$. chelonae besides other non-pathogenic species (Goodfellow \& Wayne, 1982). The grouping of rapid growers based on mycolic acid patterns was concordant with chromogenicity. Groups B and C included many chromogenic species but the mycobacteria in group A were all nonchromogenic. There is, however, no obvious correlation between the biosynthesis of carotenoid pigments and mycolic acids. Furthermore, Groups B and C included several nonchromogenic species, e.g. $\boldsymbol{M}$. diernhoferi, $M$. pulveris and $M$. agri, and there was no correlation between chromogenicity and mycolic acid patterns in the slow growers. Although chromogenicity is often used as a convenient criterion for identifying or classifying mycobacterial species, the significance of pigment production in the physiology of mycobacterial species and its taxonomic value are not yet clear (Tsukamura, 1963; Minnikin, 1982). Furthermore, during repeated culture, nonchromogenic species often acquire a slight chromogenicity which sometimes causes confusion in identification. The grouping of mycobacteria by mycolic acid patterns is more reliable because mycolic acids are always major structural components of acid-fast bacteria and many characteristic enzymes must be involved in their biosynthesis (Minnikin, 1982; Takayama \& Qureshi, 1984; Lacave et al., 1987). Furthermore mycolic acid patterns are relatively constant if the cultural conditions do not vary.

\section{REFERENCES}

Bruneteau, M. \& Michel, G. (1968). Structure d'un dimycolate d'arabinose isolé de Mycobacterium marianum. Chemistry and Physics of Lipids 2, 229-239.

Daffé, M., Lanéelle, M. A., Asselineau, C., LévyFRÉBAULT, V. \& DAVID, H. (1983). Intérêt taxonomique des acides gras des mycobactéries: proposition d'une methode d'analyse. Annales de microbiologie 134B, 241-256.

Danielson, S. J. \& Gray, G. R. (1982). Structures of the two homologous series of dialkene mycolic acids from Mycobacterium smegmais. Journal of Biological Chemistry 257, 12196-12203.

ETÉMADI, A. H. (1967). Les acides mycoliques: structure, biogenèse et intérêt phylogénétique. $E x-$ posés annuels de biochimie médicale 28, 77-109.

Etémadi, A. H., Pinte, F. \& Markovits, J. (1967). Nouvelle analyse des acides $\alpha$-mycoliques de $\mathrm{Myco}$ bacterium smegmatis. Bullétin de la Société chimique de France, 195-199.

Goodfellow, M. \& WAYNE, L. G. (1982). Taxonomy and nomenclature. In The Biology of the Mycobacteria, vol. 1, pp. 95-184. Edited by C. Ratledge \& J. Stanford. London: Academic Press.

Kaneda, K., Imaizumi, S., Mizuno, S., Tomiyasu, I., Tsukamura, M. \& Yano, I. (1986a). Rapid and precise identification of mycobacterial species by gas chromatography-mass spectrometry of mycolic acids. In Mycobacteria of Clinical Interest, pp. 115119. Edited by M. Casal. Amsterdam: Elsevier.

Kaneda, K., Naito, S., Imaizumi, S., Yano, I., Mizuno, S., TomiYasu, I., BABA, T., Kusunose, E. \& Kusunose, M. (1986 b). Determination of molecular species composition of $\mathrm{C}_{80}$ or longer-chain $\alpha$-mycolic acids in Mycobacterium spp. by gas chromato- graphy-mass spectrometry and mass chromatography. Journal of Clinical Microbiology 24, 10601070.

Kaneshiro, T. \& MarR, A. G. (1961). cis-9,10methylene hexadecanoic acid from the phospholipids of Escherichia coli. Journal of Biological Chemistry 234, 2615-2619.

KUSAKA, T. \& MORI, T. (1986). Pyrolysis gas chromatography-mass spectrometry of mycobacterial mycolic acid methyl esters and its application to the identification of Mycobacterium leprae. Journal of General Microbiology 132, 3403-3406.

Kusamuran, K., Polgar, N. \& Minnikin, D. E. (1972). The mycolic acids of Mycobacterium phlei. Journal of the Chemical Society Chemical Communications 111-112.

Lacave, C., Lanéelle, M. A., Daffé, M., MontroZIER, H., Rols, M. P. \& AsselineaU, C. (1987). Etude structurale et métabolique des acides mycoliques de Mycobacterium fortuitum. European Journal of Biochemistry 163, 369-378.

LAMonica, G. \& EtÉmadi, A. H. (1967). Nouvelle confirmation de la structure et de la biogenèse ses acides $\alpha$-avi-mycoliques. Comptes rendus hebdomadaires des séances de l'Académie des sciences $265 \mathrm{C}$, 1197-1200.

LANÉElle, M. A. \& LanÉElle, G. (1970). Structure d'acides mycoliques et d'un intermediaire dans la biosynthèse d'acides mycoliques dicarboxyliques. European Journal of Biochemistry 12, 296-300.

MINNIKIN, D. E. (1982). Lipids: complex lipids, their chemistry, biosynthesis and roles. In The Biology of the Mycobacteria, vol. 1, pp. 95-184. Edited by C. Ratledge \& J. Stanford. London: Academic Press. 
Minnikin, D. E. \& Polgar, N. (1967). The mycolic acids from human and avian tubercle bacilli. Chemical Communications 916-918.

Minnirin, D. E., Hutchinson, I. J., Caldicott, A. B. \& GoOdFEllow, M. (1980). Thin-layer chromatography of methanolysates of mycolic acid-containing bacteria. Journal of Chromatography 188, 221-233.

Minnikin, D. E., Minnikin, S. M., Goodfellow, M. \& Stanford, J. L. (1982). The mycolic acids of Mycobacterium chelonae. Journal of General Microbiology 128, 817-822.

Minnikin, D. E., Minnikin, S. M., Parlett, J. H., Goodfellow, M. \& Magnusson, M. (1984). Mycolic acid patterns of some species of Mycobacterium. Archives of Microbiology 139, 225-231.

Minnikin, D. E., Minnikin, S. M., Parlett, J. H. \& GoODFELlow, M. (1985). Mycolic acid patterns of some rapidly-growing species of Mycobacterium. Zentralblatt für Bacteriologie, Microbiologie und $\mathrm{Hy}$ giene A 259, 446-460.

Qureshi, N., Takayama, K., JoRdi, H. C. \& Schnoes, H. K. (1978). Characterization of the purified components of a new homologous series of $\alpha$-mycolic acids from $M y$ cobacterium tuberculosis $\mathrm{H}_{37} \mathrm{Ra}$. Journal of Biological Chemistry 253, 5411-5417.

TAKAYAMA, K. \& QuREshi, N. (1984). Structure and synthesis of lipids. In The Mycobacteria. A Source Book, vol. 1, pp. 361-378. Edited by G. P. Kubica \& L. G. Wayne. New York: Marcel Dekker.

Toriyama, S., Yano, I., Masui, M., Kusunose, M. \& Kusunose, E. (1978). Separation of $\mathrm{C}_{50-60}$ and $C_{70-80}$ mycolic acid molecular species and the changes by growth temperature in Mycobacterium phlei. FEBS Letters 95, 111-115.

TSUKAMURA, S. (1963). Biological significance of pigments of mycobacteria. I. Artificial induction of pigmentless mutants from photochromogens and scotochromogens by ultraviolet irradiation. II. Correlation of pigment formation with virulence. Japanese Journal of Tuberculosis 12, 1-6.

Yano, I., Kageyama, K., OhNo, Y., Masui, M., Kusunose, E., Kusunose, M. \& AKIMORI, N. (1978). Separation and analysis of molecular species of mycolic acids in Nocardia and related taxa by gas chromatography mass spectrometry. Biomedical Mass Spectrometry 5, 14-24. 